\title{
Introduction to "Leader Power and Agency-Communion Orientations as Moderators of the Effects of Organizational Characteristics on Workplace Bullying"
}

\author{
Victor G. Devinatz ${ }^{1}$
}

Published online: 12 June 2021

(C) The Author(s), under exclusive licence to Springer Science+Business Media, LLC, part of Springer Nature 2021

Bullying, which is ubiquitous in society, can be defined as behavior intending to injure, scare, or pressure a person or persons viewed as vulnerable. Types of bullying include physical bullying (hostile physical threats), verbal bullying (degrading others through utilizing cruel, demeaning words), social bullying (exclusion of individuals from groups and disseminating rumors about people) and cyberbullying (bullying through types of electronic media). Bullying often begins early in life. Statistics indicate that nine out of every ten 4th through 8th grade students have either been bullied or harassed in school or in cyberspace.

Research demonstrates that some $75 \%$ of employees have been harmed by workplace bullying defined as one or more persons participating in repeated, abusive behavior of one or more employees which negatively impacts work wherever it occurs, be it the factory, plant, or office. Workplace bullying differs from bullying at school in that bullying at work is predominantly conveyed either verbally or psychologically while school place bullying is usually more physically harmful to students.

In this timely, well-written and interesting "Perspectives" Section article, Dr. Jeffery D. Houghton, Professor of Management at West Virginia University, Mr. Richard Oxarart, Ph.D. candidate in the Department of Management at West Virginia University, Dr. Joyce Heames, Dean of the Campbell School of Business at Berry College, Dr. M. Ronald Buckley, JC Penney Company Business Leadership Chair in the Division of Management and International Business at the University of Oklahoma and Dr. Jerry Carbo, Professor of Management and Marketing at Shippensburg University have authored a conceptual paper that proposes that the difference between an autocratic and democratic leadership orientation may moderate the relationship between key organizational characteristics and workplace bullying. In particular, these scholars investigate leader autocratic versus democratic power orientations and leader agentic versus communal orientations as the theory for creating a new paradigm, in the authors' words, "of perceived leadership orientation as a moderator of the relationships between certain key organizational characteristics and perceptions of

Victor G. Devinatz

vgdevin@ilstu.edu

1 Department of Management \& Quantitative Methods, Illinois State University, Normal, IL 61790-5580, USA 
workplace bullying behavior." Moreover, the authors contend that there are "differential moderating effects" for the two leader orientations. They argue that democratic and communal leadership orientations may result in employees perceiving the occurrence of fewer incidents of workplace bullying. The authors conclude their essay by discussing the practical implications of their model and offer suggestions for future research on this topic. If any of the journal's readers are interested in responding to any essays published in the "Perspectives" Section or would like to write articles on any topics in the field of employee relations, please do not hesitate to contact me with your proposal. I welcome both practitioner-based and scholarly-based articles written from any one of a variety of theoretical perspectives. I hope that you enjoy this article and find it most illuminating.

Publisher's Note Springer Nature remains neutral with regard to jurisdictional claims in published maps and institutional affiliations. 